in contact with the tissues. The terebene group may be cited as an example. Theories, however, are not so important as clinical facts. A few brief sketches of further cases treated are appended :

Case 21.-Mrs. S., age 32, suffering from chronic gastric catarrh of unusually severe type. After six weeks daily use of oxygen (modified and diluted,) together with hot water drinking-very little attention being paid to her diet-she fully recovered, and became more robust than for many years.

Case 22.-Mrs. C. R., age 63. Suffered some years since with spinal meningitis and has never fully recovered. Convalescence was followed by epileptoid convulsions and hysterical phenomena of various kinds. At present is subject to paroxysms of dyspncea, simulating œedema of the lungs. Each paroxysm it is thought will prove fatal. Modified oxygen was carried to the bedside in rubber bags, twice daily, and during the intervals the patient was kept supplied with a solution of hydrogen dioxide which was vaporized and inhaled.

This treatment was continued for three weeks, with the gratifying result of clearing up the lungs, removing the dyspnœa, and greatly aiding the digestion, which had become seriously disordered. Nor was there any relapse on leaving off the remedy. This patient died six months later from degeneration of the cord, (at least so reported by the attending physician) the dyspnoea not having returned.

Case 23.-P. E., age 22. Subject to periodic headache of so severe a type as to have injured his memory and caused ocular troubles. The par. oxysms are generally a true migraine and of fairly explosive violence. They recur from once to three times per week quite regularly. Placed this patient on a mixture of $\mathrm{O}, \mathrm{N}_{2} \mathrm{O}$ and common air, viz. :

B. $O$, two volumes. $\mathrm{N}_{2} \mathrm{O}$ one volume. Common air three volumes.

Of which two to four gallons were inhaled night and morning.

Two weeks treatment greatly relieved the paroxysms, and in four weeks patient assures me he is no longer troubled. The head is cool, the eyes clear, and the paroxysms do not now recur.

Case 24.-Miss W. M., age 24, teacher. Has severe and constant cough, with "soreness" of the lungs, loss of appetite and general malaise. Is very much frightened lest it be already incurably seated "consumption." The family history is not favorable.

October 20.-Nut being able to come to the office for treatment, is placed upon the daily use of the portable variety. Continuing the inhalations carefully night and morning for four weeks, she reports that her cough is gone and appetite excellent. The soreness no longer troubles her, and she has given up "dying of consumption" for the present.

Case 25.-Mrs. W. A., age 62. Has been for years subject to constant neuralgia-trifacial-of the most aggravated form, accompanied by severe chronic dyspepsia. Stomach tolerates very little food of any kind, and her sufferings are agonized in the extreme. It is hardly thought that treatment will do much for her, especially since her circumstances do not per- mit the most efficient form of office treatment. Contrary to expectation, the thorough use of the portable form of oxygen four times a day is followed by marked and immediate relief of the paroxysms. The digestive system also promptly responds, and within a week or ten days she is enabled to partake of nourishing diet, and to digest it. In connection with the inhalations this patient is directed to take internally, of the ${ }_{5} 5$ volume solution of hydrogen dioxide, a teaspoonful, well diluted, before each meal.

This treatment is still being followed and improvement is steady in all directions. 49r West Twenty-Second Street.

\section{A REMARKABLE RESULT FROM AN OPERATION FOR STRANGULATED HERNIA.}

Read before the Wayne County (Indiana) Medical Society.

BY S. S. BOYD, M.D.,

$$
\text { OF DUBLIN, IND. }
$$

On May I 7, I886, I was called to see John Leeson, aged 52 years, who was suffering from direct strangulated inguinal hernia of the right side. The tumor below the ring was about five inches long and two inches thick. The symptoms which ordinarily accompany strangulated hernia, such as intense pain, sickness and vomiting, being absent, and as I had, two months before, reduced a similar strangulation in the same patient, of four days' standing, by taxis after anæsthetizing with ether, I thought it safe in this case to make an effort at reduction by the same means. Being assisted by Dr. H. B. Boyd, we had the patient placed on a broad board, which was inclined at an angle of about thirty degrees from the horizontal, with his head downwards, his head and shoulders being supported by piliows, I resorted to the usual manipulations. After pursuing this course three and a half hours we abandoned the effort in that direction.

Dr. C. N. Blount was then called in consultation, when we concluded, as the symptoms were still not urgent, to try the topical application of ice. During the next eight hours blocks of ice of about a lb. weight were continuously applied over the tumor, and warm water enemata frequently injected in to the bowels during the same period. That night a slight nausea was developed, though there was little pain or other unfavorable symptoms. The pulse, which had not been over 80 per minute, was not increased, and the temperature did not rise above $100^{\circ}$.

On the morning of May 2o, the fifth day after the strangulation occurred, believing that without the use of the knife the obstruction would not be removed, we determined on an operation. When the sac was opened it was found to contain omentum only. The distal end of the contained omentum was dark, but not gangrenous. But, in accordance with later teaching on that subject, and from the fact, as we believed, that omentum which has been strangulated over four days will not likely have its circulation restored if returned to the abdomen, we decided to ligate and excise it. We therefore ligated the protruding omentum 
in four parts, as near the point of stricture as possible, then incised the omentum as near the ligatures as practicable, and after enlarging the stricture, we returned the stump into the abdomen. After placing three deep sutures in the wound, the usual dressing completed the operation. The removed omentum weighed nine ounces. It was about four inches long and one and one-half inches thick, and nearly round, being a little larger at the proximal end.

On the 2rst the patient was resting well; pulse 100 , temperature $100^{\circ}$. On the $22 \mathrm{~d}$ the pulse was I 10 ; temperature 100 . Pulse and temperature declined from last date until the 27 th, when warm water enemata were freely used. On the 28 th, after having removed, mechanically, a large amount of impacted fæces from the rectum, the bowels were freely evacuated. On the 29 th the temperature rose to $102^{\circ}$; pulse to 100 , but both fell back to nearly normal during the next three days.

$U_{p}$ to this time the patient had been nourished entirely on milk diet. After this a little bread was added to his three meals per day.

On June 6 , seventeen days after the operation, the patient passed per anum one of the ligatures used in ligating the protruding omentum above mentioned, and at the same time there was found in the stool of the patient a piece of what was supposed to be a part of the omentum devoid of its fatty substance. The pulse and the temperature again rose to 100, but fell back to normal the next day. Three days later another one of the four ligatures used in the operation was found in one of the patient's stools.

At no time during the treatment of the case did the patient suffer much pain; and there was but little swelling of abdomen. Opium was freely used from the time of the operation until the patient was consid $\epsilon$ red out of danger. It is now nearly nine months since the operation, and the patient is well and pursuing his nccupation as a farmer.

\section{UNUSUAL CARDIAC ANOMALY.}

\section{BY A. M. HAYDEN, M.D.,}

\author{
OF EVANSVILLE, IND.
}

I wish briefly to record a case of cardiac anomaly which is altogether different from any case that I have ever seen, and so far as I can find there is no similar case on record. The case is as follows:

I was called to see the child when one week old. I found it fairly well developed, weighing eight or nine pounds, with more or less incomplete, though marked, cyanosis. Breathing was labored, and there was a slight cough. I made a diagnosis of nonclosure of the foramen ovale, and gave an unfavorable prognosis.

I was superseded by a physician of considerable reputation, who pronounced my diagnosis incorrect.

Thirteen months later I was again called to see the child. I found that it had grown but very little, and was much emaciated, not weighing more than ten or twelve pounds. It was suffering with a wellmarked case of chronic bronchitis, mucous râles be- ing distinctly heard on both lungs. I now concluded that I was mistaken in my former diagnosis, as the child was not cyanosed, the skin having regained its normal color. I treated the case for bronchitis.

Heard nothing more from case until a few days ago, when I was called on to make a post mortem examination, the child having died from the effect of disease at the end of the sixteenth month.

Autopsy revealed chronic bronchitis, with hepatization of lower lobes of both lungs. Heart enlarged. Hypertrophy of walls of ventricles. Foramen uvale pervious. Right auriculo-ventricular foramen normal. Left auriculo-ventricular foramen normal. Foramen one half inch in diameter connecting right and left ventricles. Auricles slightly dilated. The pulmonary artery took its origin from both right and left ventricles, the cavity of the artery dividing in the wall of the heart into two equal parts, one terminating in each ventricle. The aorta took its origin from left ventricle, and seemed to be normal. The pulmonary veins emptied into left auricle.

I report the above case with the hope of eliciting comment, both as to the probable cause of the condition, and as to the manner in which the circulation was carried on so as to sustain the life of the child for sixteen months. I would also like to hear of any similar cases, if there be any ors record.

Evansville, Ind., December I7, 1886.

\section{MEDICAL PROGRESS.}

Treatment of Hernia by Subcutaneous InJection.-At the meeting of the New York County Medical Society on December 27, DR. W. B. DE Garmo gave a brief history of the treatment of hernia by methods purporting to be subcutaneous, the object of all of which had been, up to the time of the publications of Heaton's method, to cause obliteration of the hernial sac. Heaton had been practicing his method, and obtaining many cures, since 1843, but he refused to make it known until i 877 . Heaton made no attempt to destroy the hernial sac; the whole object of his operation was to so fortify the fibrous tissue surrounding the canal that protrusion would not occur. His method stood alone; it differed in every way from previous methods of subcutaneous treatment; the fluid injected was astringent and mildly irritant, and its action was brought to bear upon the muscular and tendinous structures of which the inguinal canal was composed, and upon the connective tissue which bound these layers together. That improvement and practically cures would result from injections of this oak-bark solution the reader had had abundant evidence, and he could also state that it was practically without danger, at least when correctly employed. Several years ago he stood almost alone in indorsing the method, but since then it had been adopted by many others. That frequent failures had occurred was beyond question. To throw light upon the cause of some of the failures was a principal object of the paper. 